\title{
Analisa Terhadap Layanan Pasien Pada Data Warehouse RSUD Dr.R. Goeteng Taroenadibrata Purbalingga Menggunakan Laporan Olap Dengan Nine-Step Methodology
}

\author{
Pradika Destarini $^{\# 1}$, Agus Priyanto ${ }^{* 2}$, Atik Febriani ${ }^{\# 3}$ \\ \# Institut Teknologi Telkom Purwokerto \\ Jl.D.I Panjaitan No.128, Purwokerto Kidul., Purwokerto, Jawa Tengah, Indonesia \\ ${ }^{1}$ 15102110@st3telkom.ac.id, ${ }^{2}$ agus priyanto@ittelkom-pwt.ac.id ${ }^{3}$ atik@ittelkom-pwt.ac.id \\ *Fakultas Teknologi Industri dan Informatika
}

Accepted on 20-09-2019

\begin{abstract}
RSUD dr.R.Goeteng Taroenadibrata Purbalingga merupakan salah satu rumah sakit pemerintahan daerah yang sebagai pusat layanan kesehatan di Purbalingga. Setiap hari hampir ratusan pasien yang harus dilayani oleh rumah sakit tersebut, sehingga semakin bertambahnya data kunjungan pasien khususnya rawat inap dan rawat jalan yang harus dikelolapun semakin banyak. Data warehouse sendiri merupakansalah satu cara yang digunakan dalam proses analisa serta pembuatan laporan yang di butuhkan suatu perusahaan atau instansi pemerintahan pada data dengan jumlah yang banyak. Data yang digunakan dalam penelitian ini adalah data kunjungan pasien rawat jalan dan rawat inap periode tahun 2013 sampai dengan 2017. Adanya sistem laporan Online Analytical Processing (OLAP) berfungsi untuk mempermudah dan mempercepat proses pengumpulan data untuk penyajian informasi sesuai dengan kebutuhan pihak rumah sakit. Nine-Step Methodologydigunakan dalam penelitian ini sebagai pengembangan data warehouse yang meliputi Pemilihan Proses, Pemilihan Grain, Identifikasi dan Penyesuaian, Pemilihan Fakta, Penyimpanan Pre-calculation ditabel fakta, Memastikan tabel dimensi, Pemilihan durasi database, Melacak perubahan dimensi secara perlahan, sertaPenentuan prioritas dan model query. Hasil yang di dapat dalam penelitian ini dapat mempercepat dalam penyajian informasi sesuai kebutuhan sehingga mampu memaksimalkan dalam menganalisis informasi tersebut.
\end{abstract}

Keywords: Data Warehouse, Nine-Step Methodology, Online Analytical Processing (OLAP), Rawat Inap, Rawat Jalan

\section{INTRODUCTION}

$\mathbf{P}$ erkembangan teknologi dan informasi saat ini banyak digunakan dalam pengolahan data untuk menghasilkan informasi yang lebih cepat dan biasa digunakan untuk keperluan perusahaan maupun instansi pemerintahan. Seiring dengan kebutuhan manusia yang semakin tinggi maka akan menghasilkan kumpulan data yang semakin besar. Hal iniberpengaruh terhadap teknologi yangmemberikan lebih banyak kemudahan dalam mendapatkan informasi, sesuai dengan kebutuhan dalam jumlah data yang lebih besar pula. Penyajian 
informasimembutuhkan database untuk menampung data-data yang setiap saat semakin bertambah banyak sehingga ukuran database pun semakin besar. Tidak bisa dipungkiri bahwa saat ini rumah sakit di setiap harinya akan banyak pasien yang berdatangan untuk menjalankan perawatan maupun pengobatan sehingga dalam penyajian informasi juga akan semakin lamadisebabkan oleh banyaknya data.Untuk meningkatkan layanan pada rumah sakit diperlukan adanya sistem yang dapat menghasilkan informasi dengan cepat dan sesuai dengan kebutuhan sehingga dalam menyajikan laporanpun akan semakin cepat.

RSUD dr. R. Goeteng Taroenadibrata Purbalingga merupakan salah satu rumah sakit pemerintahan daerah yang terdapat pengelompokan unit. Banyaknya unit yang tersedia di rumah sakit pastinya membutuhkan sumber daya manusia sesuai dengan keahlian dibidangnya masing-masing agar pelayanan yang diberikan juga akan lebih maksimal. Pada RSUD dr. R. Goeteng Taroenadibrata dari tahun ke tahun khususnya pada rawat inap dan rawat jalan terus mengalami peningkatan pasien. Adanya jumlah data yang besar maka perlu dikembangkan sebuah sistem datawarehouse untuk memudahkan mendapatkan informasi dan membuat laporan akan cepat sesuai kebutuhan. Kunjungan pasien rawat inap dan rawat jalan diambil dari tahun 2013 sampai dengan 2017.Jumlah pasien rawat inap sebanyak 85.664 pasien dan rawat jalan 667.898 pasien.

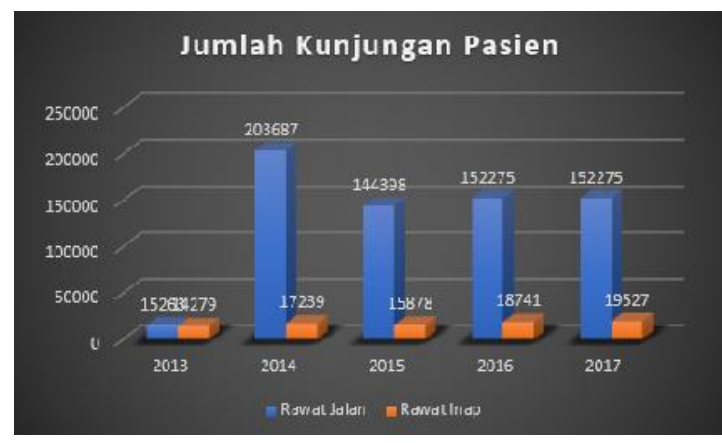

Gambar 1. Data Kunjungan Pasien Rawat Inap dan Rawat Jalan

Berdasarkan deskripsi diatas maka disusun penelitian dengan judul "Analisa terhadap Layanan Pasien pada Data Warehouse RSUD dr.R. Goeteng Taroenadibrata menggunakan Laporan OLAP dengan Nine-Step Methodology". Adapun yang menjadi alasan dilakukan penelitian dengan judul tersebut adalah untuk mempercepat proses pengumpulan data untuk penyajian informasi sehingga mampu memaksimalkan kualitas layanan dari pihak rumah sakit dengan menerapkan OLAP untuk mendapatkan laporan yang diperlukan sesuai dengan kebutuhan pihak rumah sakit.

\section{A. Penelitian Sebelumnya}

\section{LITERATURE REVIEW}

Penelitian yang berkaitan dengan datawarehouse untuk membuat laporan menggunakan OLAP dan analisis kunjungan pasien bukan kali pertama dilakukan. Penelitian ini akan membahas mengenai analisa pada kunjungan pasien berdasarkan unit rawat inap dan rawat jalan yang diterapkan pada OLAP untuk mendapatkan informasi sesuai kebutuhan.

Penelitian dari Nur Ardista, Taufik, Purbandini dari Fakultas Sains dan Teknologi di Universitas Airlangga Kampus C Mulyorejo, Surabaya dengan judul "Rancang Bangun Data Warehouse untuk Pembuatan Laporan dan Analisis pada Data Kunjungan Pasien Rawat Jalan Rumah Sakit Universitas Airlangga Berbasis Online Analytical Processing (OLAP)". Masalah yang diangkat yaitu dikarenakan pihak rekam medis mengalami kesulitan dalam membuat laporan kunjungan pasien pada unit rawat jalan. Adanya Datawarehouse menghasilkan sistem OLAP yang digunakan untuk membantu kinerja pihak rekam medis RSUA sehingga dapat menangani kendala pada informasi laporan yang perhitungannya masih secara manual sesuai dengan format yang dibutuhkan[1]. 
Adapun penelitian serupa yang telah dilakukan oleh Totok Suprawoto, Enny Itje Sela dan Syamsu Windarti dengan judul "Prototipe Integrasi Data Morbiditas Pasien Puskesmas ke dalam Data Warehouse di Dinas Kesehatan Kabupaten Bantul”. Permasalahan yang dialami pada penelitian ini dalam membuat laporan masih secara manual namun pihak puskesmas di haruskan membuat laporan secara rutin yang akan di tujukan ke Dinas Kesehatan kabupaten Bantul sehingga mengakibatkan informasi yang di dapatkan kurang tepat waktu. Adanya datawarehouse pada puskesmas di kabupaten Bantul menghasilkan laporan berupa raw data yang diinginkan oleh Dinas Kesehatan tanpa harus meminta laporan ke masing-masing puskesmas[2].

\section{B. Dasar Teori}

\section{DataWarehouse}

Data Warehouse merupakan sebuah gudang data yang berisi data dalam jumlah besar dan digunakan untuk proses analisa serta pembuatan laporan yang dibutuhkan suatu perusahaan atau instansi pemerintahan. Hal ini dapat diperkuat dari beberapa ahli seperti Han Jiwai, W.H Inmon dan lainnya. Menurut W.H Inmon dalam bukunya Building The Data Warehouse (2005), Data Warehouse adalah koleksi data yang mempunyai sifat berorientasi subjek (subject-oriented), terintegrasi dan konsisten (Integrated and Consistent), time varian dan bersifat tetap, serta tidak berubah (Non Volatile)[3].

\section{ETL(Extract, Transform, And Load)}

Menurut Ralph Kimball dan Joe Caserta, ETL merupakan langkah dalam pemrosesan data padadatabase yang melibatkan kegiatan proses ekstraksi dari data sumber yang akan di transformasikan kemudian dialirkan atau di teruskan ke datawarehouse[4].

\section{Nine-Step Methodology}

Perancangan Data Warehouse menggunakan Nine-Step Methodology meliputi Pemilihan Proses, Pemilihan Grain, Identifikasi dan Penyesuaian, Pemilihan Fakta, Penyimpanan pre-calcultion di tabel fakta, Memastikan tabel dimensi, Pemilihan durasi database, Melacak perubahan dimensi secara perlahan, serta Penentuan prioritas dan model query[5].

\section{OLAP (Online Analytical Processing)}

Online Analytical Processing merupakan metode untuk menampilkan informasi dari permintaan proses analisis yang bersifat dimensional secara cepat dengan menggunakan aplikasi dan teknologi yang dapat mengoleksi, menyimpan, memanipulasi suatu data multidimensi untuk tujuan analisis. OLAP juga bagian dari kategori yang lebih global dari sebuah konsep yang juga merangkum hubungan antara pelaporan dan penggalian data. OLAP mampu menunjukan kepada pengguna bagaimana data-data dikumpulkan dari sumber data hingga data dapat diseragamkan dan di analisis guna memperoleh informasi didalamnya[6].

\section{Framework Codeigniter}

Framework CodeIgniter adalah framework PHP yang membantu mempercepat dalam mengembangkan aplikasi web berbasis PHP dibandingkan dengan menulis semua code program dari awal[7].

\section{6. $M y S Q L$}

MySQL merupakan turunan salah satu konsep utama dalam database terutama untuk pemilihan atau seleksi dan pemasukan data yang memungkinkan pengoperasian data dikerjakan dengan mudah secara otomatis[8].

\section{7. $X A M P P$}

$X A M P P$ berfungsi sebagai server yang berdiri sendiri (localhost), terdiri atas program Apache HTTP Server, MySQL database, dan penerjemahan bahasa dengan bahasa pemrograman PHP dan Perl. Program ini tersedia dalam GNU General Public License dan bebas, merupakan web server yang mudah digunakan supaya tampilan halaman web dinamis[9]. 


\section{RESEARCH METHOD}

\section{A. Studi Literatur}

Studi literatur pada penelitian ini merujuk pada penelitian sebelumnya yang masih berkaitan dengan topik. Studi literatur yang dilakukan dengan cara membaca dan memahami jurnal yang terkait dengan penelitian seperti metode ataupun studi kasus yang digunakan sebagai acuan untuk pembahasan pada penelitian ini

\section{B. Pengumpulan Data}

Pengumpulan data dilakukan melalui data primer dimana menggunakan teknik secara observasi, wawancara serta pengambilan data dari tahun 2013 sampai dengan 2017 melalui dokumen tertulis yang digunakan untuk mendukung kelengkapan pada penelitian.

\section{Perancangan Proses ETL DataWarehouse}

Pada perancangan proses ETL Datawarehouse, ETL melakukan beberapa proses sesuai dengan fungsinya dimana Extract adalah data sumber yang kemudian akan di proses melalui transform, setelah melalui kedua tahap selanjutnya akan masuk proses load dimana data akan ditampilkan di halaman sistem atau OLAP[10].

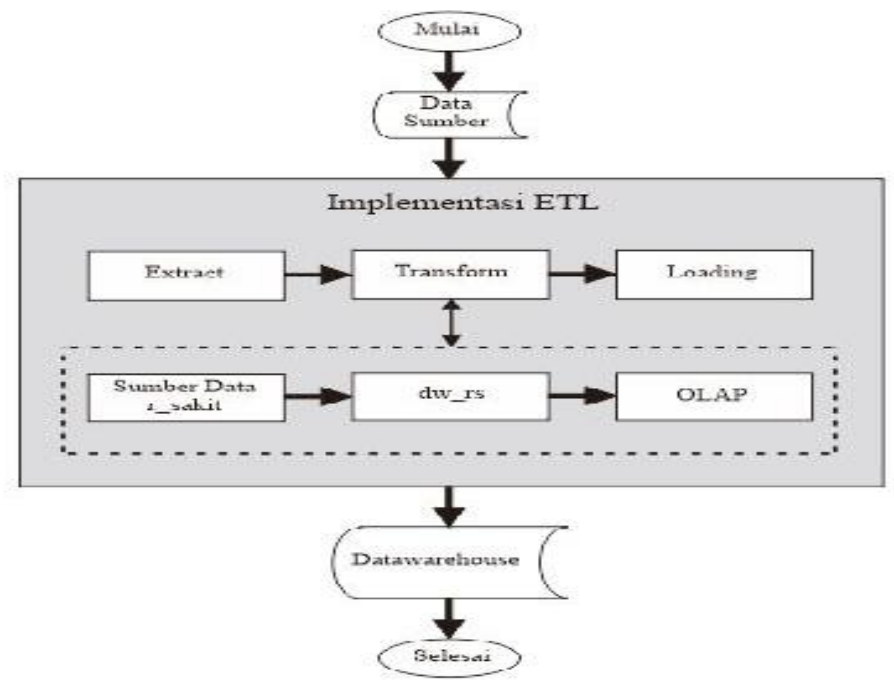

Gambar 2. Proses ETL Datawarehouse

\section{Perancangan Laporan OLAP}

Pada perancangan laporan OLAP, data yang berada di database $r_{-}$sakit (sumber data) diterapkan ke dalam nine-step methodology terlebih dahulu agar mendaparkan hasil OLAP yang lebih baik. 


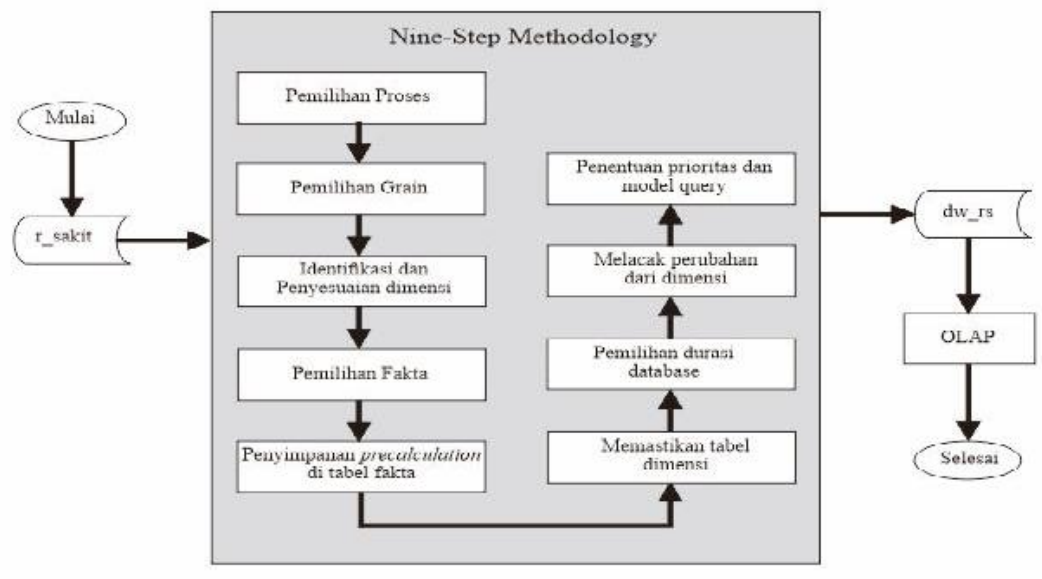

Gambar 3. Flowchart proses Nine-Step Methodology

Laporan OLAP dengan penerapan Nine-Step Methodology adalah laporan kunjungan pasien khususnya rawat inap dan rawat jalan yang dibutuhkan oleh pihak rekam medis.

\section{E. Gambaran Umum Rancangan Sistem}

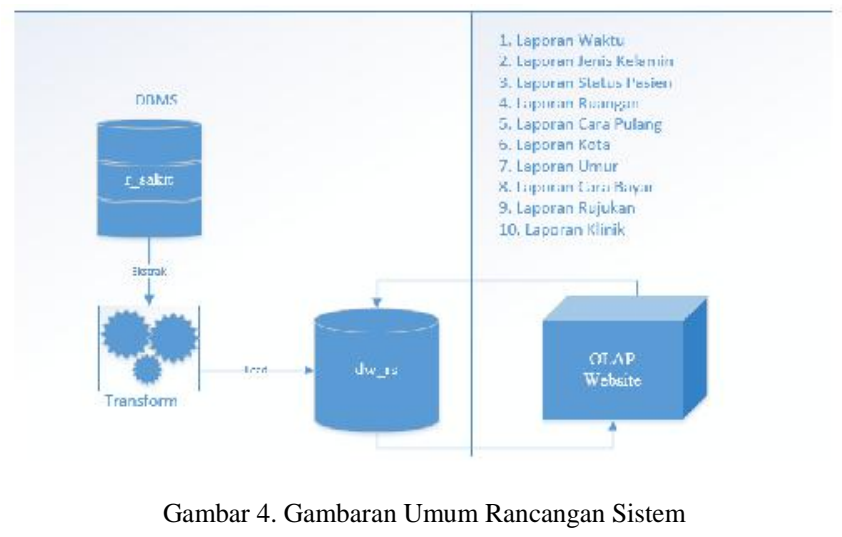

Gambaran umum rancangan sistem dimana DBMS atau database r_sakit berisikan semua data kunjungan pasien rawat jalan dan rawat inap dari tahun 2013 sampai dengan 2017, lalu melalui tahap ETL yang mana data tersebut setelah di ekstrak kemudian masuk ke dalam Data staging area yang berfungsi untuk menyediakan tempat bagi proses transform atau masuk ke dalam databasse dw_rs. Setelah proses ETL berjalan maka data akan tampil pada OLAP. Dimana laporan OLAP yang dibutuhkan di dalam kunjungan pasien rawat jalan dan rawat inap ada 10 seperti yang tercantum pada Gambar 4.

\section{RESULTS AND DisCUSSION}

\subsection{Penerapan Datawarehouse menggunakan Nine-Step Methodology}

a. Pemilihan Proses

Berdasarkan pada ruang lingkup yang dibutuhkan, maka dilakukannya pemilihan proses yang akan digunakan dalam perancangan nantinya. Proses yang dipilih yaitu rawat jalan dan rawat inap. 


\section{b. Pemilihan Grain}

Pada tahap grain menentukan record di dalam tabel fakta yang akan digunakan untuk membangun data warehouse, sebagai berikut.

\section{1) Rawat Inap}

Pemilihan grain yang dilakukan pada rawat inap merupakan jumlah pasien rawat inap berdasarkan Waktu, Jenis Kelamin, Status Pasien, Ruang, Kelas, Cara Pulang, Provinsi, Kabupaten, Kecamatan, Umur, Cara Bayar dan Rujukan.

\section{2) Rawat Jalan}

Pemilihan Grain yang dilakukan pada rawat jalan merupakan jumlah pasien rawat jalan berdasarkan Waktu, Jenis Kelamin, Provinsi, Kabupaten, Kecamatan, Klinik dan Asuransi.

c. Identifikasi dan Penyesuaian dimensi

Pada tahap ini, membangun atau mengidentifikasi dimensi yang dipilih untuk mengatur konteks tentang fakta di dalam tabel fakta, Sebagai berikut

\section{1) Rawat Inap}

Dimensi yang dilakukan pada rawat inap untuk analisis yaitu dimensi Waktu, Jenis Kelamin, Status Pasien, Ruangan, Cara Pulang, Kecamatan, Umur, Cara Bayar dan Rujukan.

\section{2) Rawat Jalan}

Dimensi yang dilakukan pada rawat jalan untuk analisis yaitu dimensi Waktu, Jenis Kelamin, Kecamatan, Klinik dan Asuransi.

d. Pemilihan Fakta

Pada tahap ini melakukan pemilihan fakta yang akan digunakan untuk tabel pada rawat inap dan rawat jalan, sebagai berikut :

1) Fakta Rawat Inap

Tabel1

Pemilihan Fakta Rawat Inap

\begin{tabular}{|c|c|c|}
\hline Nama Kolom & Tipe Data & Panjang \\
\hline kdwaktu & Datetime & \\
\hline kdjeniskelamin & Varchar & 25 \\
\hline kdsp & Varchar & 25 \\
\hline kdkelas & Varchar & 25 \\
\hline kdruangan & Varchar & 25 \\
\hline kdarapulang & Varchar & 11 \\
\hline idkecamatan & Int & 11 \\
\hline idkabupaten & Int & 100 \\
\hline kdumur & Char & 25 \\
\hline kdcarabayar & Varchar & Varchar \\
\hline kdrujukan & &
\end{tabular}


2) Fakta Rawat Jalan

Tabel 2

Pemilihan Fakta Rawat Jalan

\begin{tabular}{|c|c|c|}
\hline Nama Kolom & Tipe Data & Panjang \\
\hline kdwaktu & Datetime & \\
\hline kdjeniskelamin & Varchar & 25 \\
\hline idkecamatan & Int & 11 \\
\hline idkabupaten & Int & 11 \\
\hline kdklinik & Varchar & 25 \\
\hline kdasuransi & Varchar & 25 \\
\hline
\end{tabular}

e. Penyimpanan Pre Calculation Di Tabel Fakta

Kalkulasi fakta rawat inap dan rawat jalan yang terdapat pada tabel fakta, sebagai berikut:

1) Fakta Rawat Inap

Kalkulasi pada fakta rawat inap merupakan jumlah pasien berdasarkan Jenis Kelamin, Status Pasien, Ruang, Kelas, Cara Pulang, Provinsi, Kabupaten, Kecamatan, Umur, Cara Bayar, Rujukan dan total pasien.

\section{2) Fakta Rawat Jalan}

Kalkulasi pada fakta rawat jalan merupakan jumlah pasien berdasarkan Jenis Kelamin, Provinsi, Kabupaten, Kecamatan, Klinik, Asuransi dan total pasien rawat jalan.

f. Memastikan Tabel Dimensi

Pada tahap ini menambahkan keterangan di setip dimensi untuk mempermudah pengguna.

Tabel 3

Memastikan tabel dimensi pada rawat inap dan rawat jalan

\begin{tabular}{|l|l|l|}
\hline \multicolumn{1}{|c|}{ Dimensi } & \multicolumn{1}{c|}{ Field } & \multicolumn{1}{c|}{ Keterangan } \\
\hline Waktu & tgl_masuk & Analisis jumlah pasien perTahun \\
\hline Jenis Kelamin & w_jk & Analisis jumlah pasien berdasarkan jenis kelamin \\
\hline Status Pasien & w_sp & Analisis jumlah pasien berdasarkan status pasien \\
\hline Ruangan & w_ruangan & Analisis jumlah pasien berdasarkan kelas dan ruangan \\
\hline Cara Pulang & w_carapulang & Analisis jumlah pasien berdasarkan cara pulang \\
\hline Kecamatan & namakecamatan & $\begin{array}{l}\text { Analisis jumlah pasien berdasarkan provinsi, kabupaten, } \\
\text { kecamatan }\end{array}$ \\
\hline Umur & umur_mulai , umur_akhir & Analisis jumlah pasien berdasarkan umur \\
\hline Cara Bayar & w_carabayar & Analisis jumlah pasien berdasarkan cara bayar \\
\hline Rujukan & w_rujukan & Analisis jumlah pasien berdasarkan rujukan \\
\hline Klinik & w_klinik & Analisis jumlah pasien berdasarkan klinik \\
\hline Asuransi & w_asuransi & Analisis jumlah pasien berdasarkan asuransi \\
\hline
\end{tabular}




\section{g. Pemilihan Durasi Database}

Durasi yang dimasukkan di dalam database selama lima tahun dari tahun 2013 sampai dengan 2017.

h. Melacak Perubahan Dari Dimensi

Atribut yang memungkinkan dapat berubah karena pada tabel dimensi dapat terjadi perubahan dalam waktu yang cukup lama. Terdapat tiga tipe dasar dalam melakukan perubahan pada atribut dimensi yaitu menulis ulang atribut, membuat record dan membuat kolom baru. Pada perubahan ini membuat record baru, sebagai berikut.

Tabel 4

Perubahan Dimensi

\begin{tabular}{|l|l|}
\hline \multicolumn{1}{|c|}{ Dimensi } & \multicolumn{1}{|c|}{ Atribut yang dapat berubah } \\
\hline dim_jeniskelamin & w_jk \\
\hline dim_statuspasien & w_sp \\
\hline dim_ruangan & w_ruangan \\
\hline dim_carapulang & w_carapulang \\
\hline dim_kota & namakecamatan, namakabupaten \\
\hline dim_umur & umur_awal, umur_akhir \\
\hline dim_carabayar & w_carabayar \\
\hline dim_rujukan & w_rujukan \\
\hline dim_klinik & w_klinik \\
\hline dim_asuransi & w_asuransi \\
\hline
\end{tabular}

i. Penentuan Prioritas dan Model Query

Mempertimbangkan pengaruh pada perancangan upaya untuk menjaga keamanan dengan cara memproteksi data yang digunakan OLAP

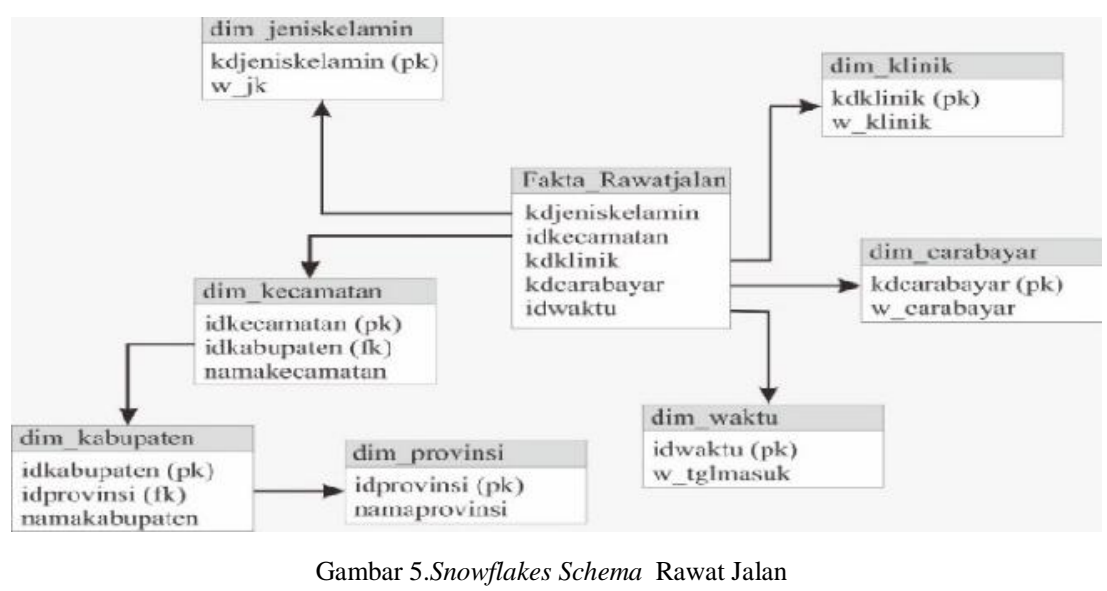




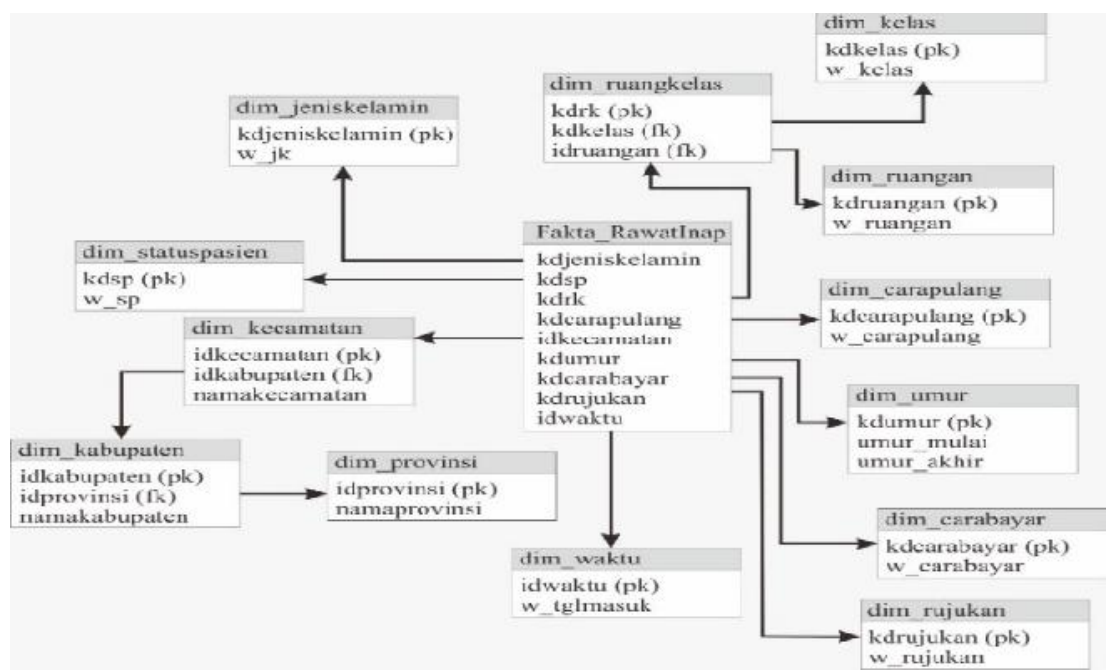

Gambar 5.SnowflakesSchema Rawat Inap

\subsection{Penerapan ETL}

a. Extract merupakan sebagai sumber data yang berasal dari database dimana data-datanya telah di tampung menjadi satu ke dalam database yang siap untuk melakukan proses transform. Database r_sakit adalah sumber data dimana data rawat inap dan rawat jalan dari tahun 2013 sampai dengan 2017 telah dimasukkan ke dalam database yang siap untuk melakukan proses selanjutnya.

b. Transform. Pada proses ini, data-data hasil ekstraksi yang berada pada r_sakit akan ditransformasikan ke dalam satu database lagi untuk menampung hasil dari transformasi. Database dw_rs merupakan hasil transformasi atau datamart dimana hanya memuat data sesuai dengan kebutuhan atau analisis.

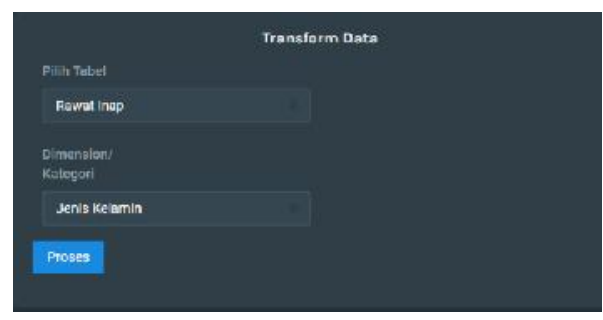

Gambar 6. Halaman Transorm Data

Proses transform disediakan pada halaman web transformasi untuk mempermudah saat proses merubah dari database r_sakit ke dalam dw_rs untuk menampung data-data yang di perlukan. Misalkan proses transformasi data pada rawat inap dengan kategori jenis kelamin maka ketika klik pada button proses maka akan memproses data.

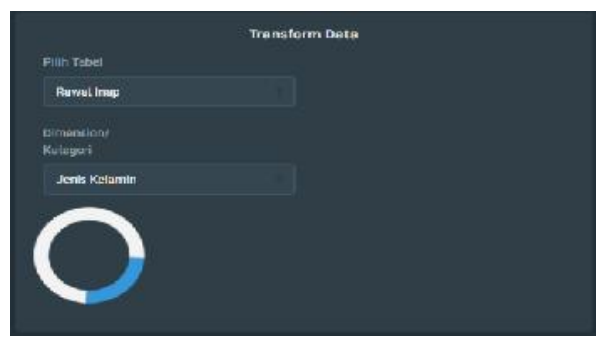

Gambar 7. Menunggu Proses Transform 


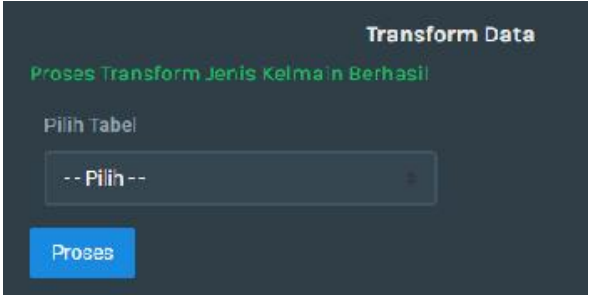

Gambar 8. Proses Transform Berhasil

Biasanya dalam memproses data tersebut membutuhkan beberapa menit sampai proses benar-benar selesai. Jika proses selesai maka akan muncul pesan bahwa "Proses Transform Jenis Kelamin Berhasil". Proses tersebut berhasil menambahkan ke dalam database dw_rs.

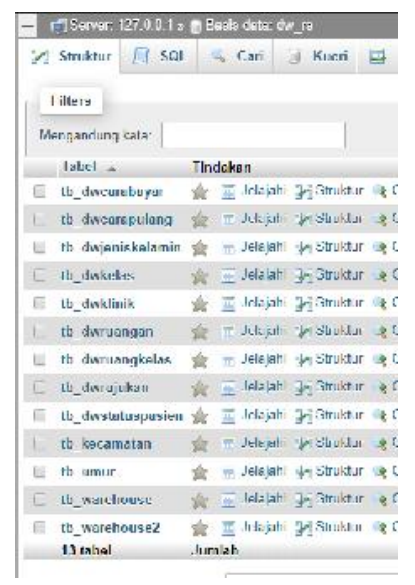

Gambar 9. Database Datawarehouse

Database pada dw_rs dimana digunakan untuk menampilkan hasil tabel pada halaman laporan OLAP.

c. Load

Pada tahap ini, data yang telah di proses pada dw_rs akan di teruskan (load) ke sistemnya dimana pengguna dapat mengaksesnya. Keluaran dari tahapan loading berupa bentuk data maupun informasi untuk kebutuhan analisis atau laporan sesuai dengan kebutuhan.

Pada rawat inap penyajian informasi yang di tampilkan berupa waktu, jenis kelamin, status pasien, ruangan, cara pulang, kota, umur, cara bayar dan rujukan, dimana ruangan di ambil dari ruang dan kelas pada rumah sakit sedangakn kota diambil dari provinsi, kabupaten kemudian kecamatan sebagai bentuk dalam informasi.

Pada rawat jalan penyajian informasi hanya berupa waktu, jenis kelamin, kota, klinik dan cara bayar. Kota sendiri diambil dari provinsi, kabupaten kemudian kecamatan sebagai acuannya.

\subsection{Penerapan OLAP}

Menerapkan laporan olap berdasarkan jenis kelamin pasien pada rawat inap.Jenis kelamin menunjukan jumlah pasien dimana kategorinya meliputi perempuan dan laki-laki. Parameter yang digunakan untuk menentukan jumlah pasien berdasarkan tahun dan bulan melalui pivot tabel serta grafik. 


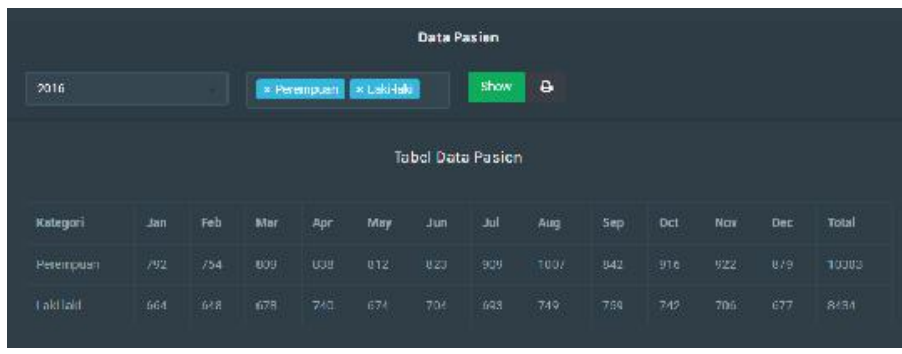

Gambar 10. PivotTable kategori Jenis Kelamin

Ketika hanya menginginkan perempuan saja atau laki-laki saja pada tahun tertentu cukup dengan memilih salah satu atau dapat menghapus salah satunya, namun pada tabel tersebut penulis mengambil data untuk perempuan dan laki-laki.

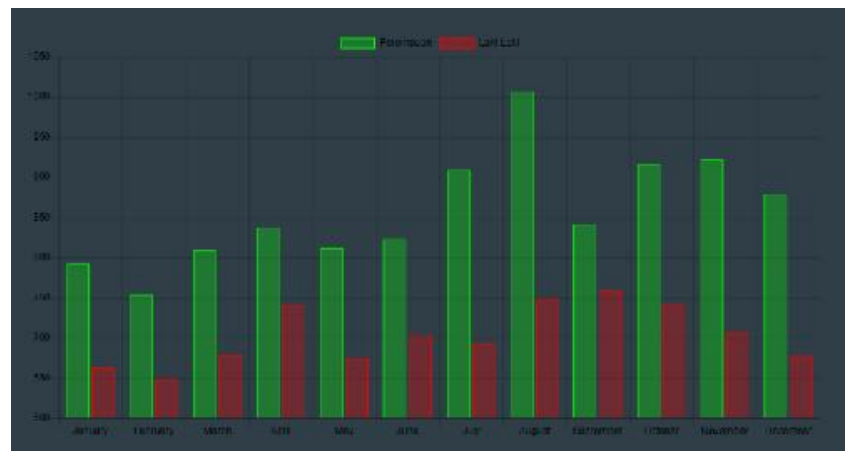

Gambar 11.Grafik Kategori Jenis Kelamin Perempuan Dan Laki-Lak

Grafik perempuan telah di jelaskan pada laporan OLAP berbasis website ini dengan warna hijau sedangkan merah untuk laki-laki atau bisa melihat keterangan yang berada di atas grafik.

Saat menginginkan laporan berupa table dan grafik tersebut bisa langsung cetak melalui tombol print yang sudah di sediakan.

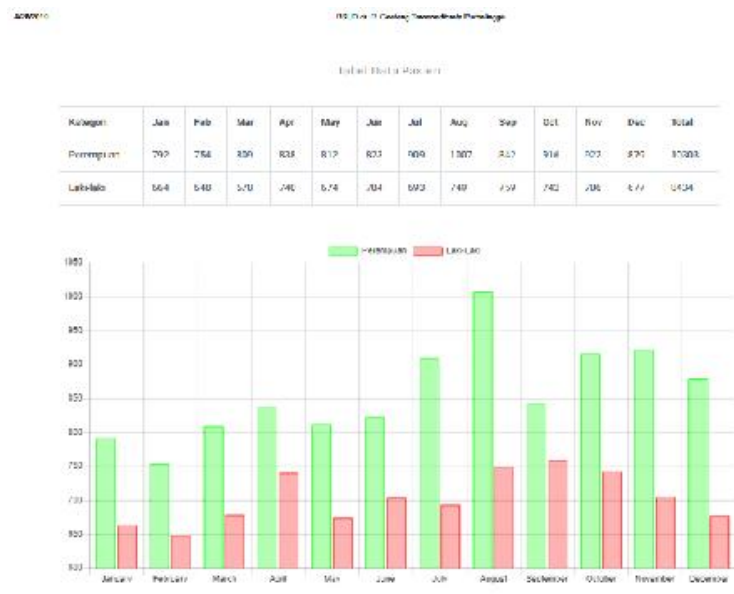

Gambar 12. Hasil Export Data Pasien Jenis Kelamin

Pada jenis kelaminpun terdapat laporan yang berupa data pasien dan rekap data. Fungsinya sama seperti yang lainnya melainkan jika memilih data pasien Tedapat pilihan ketika akan mengexport data pasien 
berdasarkan jenis kelamin, bisa memilih laki-laki, perempuan, atau laki-laki dan perempuan pada bulan dan tahun yang telah di tentukan. Format file hanya berupa excel serta CSV untuk data pasien.

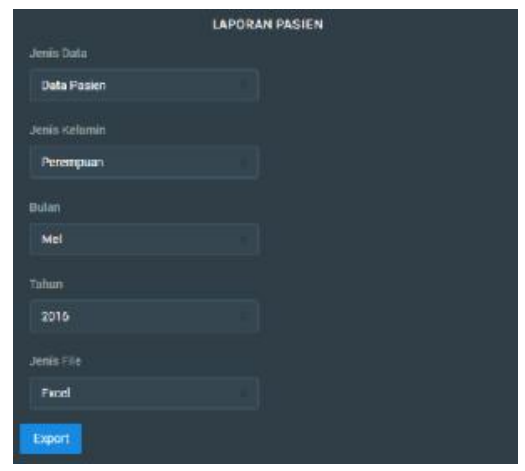

Gambar 13.Laporan Pasien Jenis Kelamin Berdasarkan Data Pasien

Misal mengambil data pasien dengan jenis kelamin perempuan di bulan Mei 2016 dengan format excel, maka saat data pasien tersebut di export akan download data pasien rawat inap.

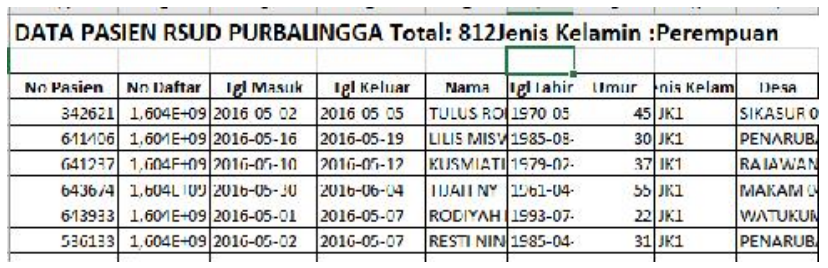

Gambar 14. Hasil Export Data Pasien Jenis Kelamin Perempuan

Hasil dari export data pasien dengan jenis kelamin perempuan pada bulan Mei 2016 berjumlah812. Data pasien di excel dengan atribut no pasien, no daftar, tanggal masuk, tanggal keluar, nama, tanggal lahir, umur, jenis kelamin, desa, kecamatan, kabupaten, rujukan, ruang, kelas, dokter, debitur, deskripsi, diag2, diag3, diag4, diag5, status pasien dan cara pulang.

\section{RESUlTS AND DiscUSSION}

Berdasarkan hasil penelitian yang dilakukan, bahwa analisa terhadap layanan pasien menggunakan Sistem laporan OLAP Data warehouse dapat diambil kesimpulan sebagai berikut:

a. Nine-Step Methodology dan ETL diterapkan dalam membangun data warehouse.

b. Sistem Laporan OLAP dapat memberikan kemudahan dan mempercepat dalam melakukan proses analisis.

c. Data yang dimasukkan ke dalam database datawarehouse disesuaikan dengan kebutuhan pihak pimpinan yang meliputi tabel waktu, jenis kelamin, status pasien, ruangan, ruang kelas, cara pulang, kecamatan, umur, cara bayar, rujukan, klinik, asuransi.

d. Mendapatkan hasil analisa kunjungan pasien menggunakan sistem Laporan OLAP berupa data pasien dan rekap data dengan format excel, csv, pdf serta grafik.

\section{ACKNOWLEDGEMENT}

Terimakasih peneliti ucapkan kepada Allah SWT sehingga peneliti sudah sampai pada tahap ini, tidak lupa kepada pembimbing atas arahan dan bimbingannya sehingga peneliti dapat menyelesaikan penelitian ini dengan baik dan kepada kaluarga serta teman-teman yang senantiasa selalu memberikan doa, semangat, dan motivasinya. Peneliti berharap, hasil penelitian ini dapat memberikan manfaat bagi pembaca. 


\section{REFERENCES}

[1] N. Ardista, "Rancang Bangun Data Warehouse Untuk Pembuatan Laporan dan Analisis pada Data Kunjungan Pasien Rawat Jalan Rumah Sakit Universitas Airlangga Berbasis Online Analytical Processing ( OLAP),” Inf. Syst. Eng. Bus. Intell., vol. 3, no. Data Warehouse, 2017

[2] T. Suprawoto, E. I. Sela, and S. Windarti, "Prototipe Integrasi Data Morbiditas Pasien Puskesmas ke dalam Data Warehouse di Dinas Kesehatan Kabupaten Bantul,” J. Inform. dan Komput., vol. 2, no. 2, pp. 83-92, 2017.

[3] T. Oktavia, "Perancangan Model Data Warehouse dalam Mendukung Perusahaan Jasa Pengiriman," semnasIF, no. Model Data Warehouse, pp. 93-100, 2011.

[4] I. P. A. E. Pratama, HANDBOOK DATA WAREHOUSE. 2017.

[5] M. Suzana, Jemakmun, and Suyanto, "Analisis Dan Perancangan Data Warehouse Rumah Sakit Umum Daerah Palembang Bari," J. Ilm. Tek. Inform. Ilmu Komput., vol. 12, no. Perancangan Data Warehouse, pp. 1-14, 2013.

[6] A. Supriyatna, "Sistem Analisis Data Mahasiswa Menggunakan Aplikasi Online Analytical Processing (Olap) Data Warehouse," $J$ Pilar Nusa Mandiri, vol. 12, no. Analisis Data Mahasiswa, pp. 62-71, 2016.

[7] S. Gi and M. D. P. Palembang, "Penerapan Data Warehouse dan Data Mining untuk Pengambilan Keputusan Pemasaran Terhadap Data Penjualan Perusahaan Retail menggunakan Algoritma Apriori,” STMIK MDP Bus. Sch., no. 10, pp. 1-13, 2018.

[8] N. Caniati, A. L. Ghozali, and A. Sumarudin, "Implementasi Sistem Informasi Pemesanan Menu Makanan dan Minuman pada Kafe Berbasis Web Menggunakan Jaringan Internet,” J. Ilm. Ilmu Komput., vol. 3, no. 2, pp. 8-13, 2017.

[9] D. Priyanti and S. Iriani, "Sistem Informasi Data Penduduk Pada Desa Bogoharjo Kecamatan Ngadirojo Kabupaten Pacitan," IJNS, vol. 2, no. 4, pp. 55-61, 2013.

[10] M. JRP, Pentaho: Solusi Open Source untuk Membangun Data Warehouse. 2014. 